\title{
Optimizing the time performance of subcontractors in the building projects
}

Andy K.W. Ng, (Division of Building Science and Technology, City University of Hong Kong, Hong Kong)

Andrew D. F. Price, (Department of Civil and Building Engineering, Loughborough University, UK)

\begin{abstract}
The main contractors of Hong Kong building projects tend to subcontract most of their work. However, many of the subcontractors complain that they are not being fully utilized due main contractors' poor site coordination of temporary works and interfacing works and plant supports etc. A list of critical site coordination problems caused by main contractors that had adversely influence to the time performance of subcontractors was prepared. A questionnaire survey was conducted to collect data to generate multiple regression equations that explain how the critical site coordination problems affected the time performance of different types of subcontractor. The survey results were validated by neural network analysis. Backward elimination method was adopted to identify the 'most critical' site coordination problems that enable main contractors to formulate measures to enhance their site management system.
\end{abstract}

Keywords: Subcontractor, Site coordination problem, Time performance

\section{Introduction}

\section{Subcontracting}

Subcontracting is very important to the Hong Kong construction industry as labour-only subcontractors and fee subcontractors contributed 24 per cent and 42 per cent of the gross value of construction work performed in 2008, according to government statistics. This approach has been in operation for a long period of time in Hong Kong as a strategy to deal with long-term environmental uncertainties and to buffer the technical core of main contractors against short-term contingencies (Sozen, 1999). However, the approach creates problems, such as greater demand in coordination to subcontractors' work. Recently, most subcontractors in Hong Kong complain that they are unable to efficiently and effectively perform their site works due to main contractors' poor site coordination.

\section{Critical Site Coordination Problems}

Nineteen common site coordination problems caused by the main contractors that adversely influence subcontractors' site work were identified through literature review, observed common industrial practices and advice from experienced industrial practitioners. They were classified into eight groups of problems according to their nature as shown in Table 1. Among them, six critical problems listed in Table 2 were shortlisted by a questionnaire survey that assessed the aggregated importance score of each site problem ( $\mathrm{Ng}$ and Price, 2005). An aggregated importance score was designed based on the model developed by Kadir et al (2005). It was taken as the combined score of frequency of occurrence and the potential degree of impact to the performance of subcontractors.

\section{Aim and Objectives}

There has been considerable amount of research aimed at identifying the success factors to a building project; however, most were focused on the main contract level only. The role of main contractor has gradually transformed from a constructor to a manager of subcontractors due to the rapid development in terms of complexity and size of Hong Kong building projects in the last few decades. Frisby (1990) defined the management of the subcontractors as one of the key functions of the main contractor. This paper aims to investigate the impact of the 
critical site coordination problems to the time performance of subcontractors in the Hong Kong building projects. This aim was achieved through the following objectives.

(a) Develop multiple regression equations to explain how the critical site coordination problems caused by main contractors affect the time performance of subcontractors.

(b) Identify the 'most critical' site coordination problems by backward elimination method that enables main contractors to develop a framework to improve site coordination.

This study only covers building projects as civil engineering projects are not too labour intensive and involves fewer trades. As a result, civil engineering contractors do not subcontract their work to the same degree of building project contractors.

\begin{tabular}{|c|c|}
\hline Group: & Construction information \\
\hline \multirow[t]{2}{*}{ Problems: } & a. information not detail enough \\
\hline & b. unclear or contradictory information \\
\hline Group: & Working programme \\
\hline \multirow[t]{4}{*}{ Problems: } & a. working programme not detail enough \\
\hline & b. working sequence not practical \\
\hline & c. short notice for commencing site work \\
\hline & d. late change of working programme \\
\hline Group: & Preparation for work place \\
\hline \multirow[t]{3}{*}{ Problems: } & $\begin{array}{l}\text { a. work place environment not yet prepared such as general site } \\
\text { cleaning, fresh air supply, lighting }\end{array}$ \\
\hline & b. inadequate or insufficient site reference points \\
\hline & $\begin{array}{l}\text { c. inadequate or insufficient temporary work support such as scaffolding, } \\
\text { water \& power supply }\end{array}$ \\
\hline Group: & Interfacing work to be completed by other subcontractors \\
\hline \multirow[t]{2}{*}{ Problems: } & a. work not yet completed \\
\hline & b. work not accurately completed \\
\hline Group: & Access to work place \\
\hline \multirow[t]{2}{*}{ Problems: } & a. access road not yet ready \\
\hline & b. access routing not convenient \\
\hline Group: & Plant support \\
\hline \multirow[t]{2}{*}{ Problems: } & a. late to provide plant support \\
\hline & b. type of plant provided not appropriate \\
\hline Group: & Material support \\
\hline \multirow[t]{2}{*}{ Problems: } & a. insufficient amount \\
\hline & b. type of material provided not appropriate \\
\hline Group: & Response to site problem \\
\hline \multirow[t]{2}{*}{ Problems: } & a. late response to site problems \\
\hline & b. solution recommended not practical \\
\hline
\end{tabular}

Table 1 Common site coordination problems

Ng, A K W and Price, N D F (2010) 'Optimizing the time performance of subcontractors in the building projects', Australasian Journal of Construction Economics and Building, 10 (1/2) 90-102 


\begin{tabular}{|l|l|}
\hline Site coordination problem & Code \\
\hline Short notice to commence site work & SCP1 \\
\hline Late to provide plant support & SCP2 \\
\hline Interfacing work not yet completed & SCP3 \\
\hline Interfacing work not accurately completed & SCP4 \\
\hline Construction information not detail enough & SCP5 \\
\hline Construction information unclear or contradictory & SCP6 \\
\hline
\end{tabular}

Table 2 Critical site coordination problem coding system

\section{Research Methodology}

\section{Data Collection}

Questionnaire survey method was adopted in this study. The questionnaires were distributed to industrial practitioners through private relationship and posted to subcontracting firms based on the information provided in the Hong Kong Builders Directory. Only the respondents performing a subcontractor role in building projects were included in the data analysis. They were requested to complete the questionnaire based on their current projects or the projects with highest contract sum if they were handling several projects at the same time currently. In the questionnaire, they were requested to rate: from 0 (never happen) to 10 (happen every site activities) with 0.5 interval for the frequency of occurrence for each of the six critical site coordination problems; and from $0(0 \%)$ to $10(100 \%)$ with 0.5 interval for the achievement of time performance in their current projects at the time they filled the questionnaire. Achievement of time in their projects was estimated by comparing the actual construction time with the planned programme.

\section{Statistical Technique}

The flow chart developed by Kinnear and Gray (2008) classified the nature of the research work into five types for the selection of the appropriate statistical technique for data analysis as per Figure 1. As the nature of this research relates to the prediction of outcomes, multiple regression analysis is considered an appropriate approach for this study.

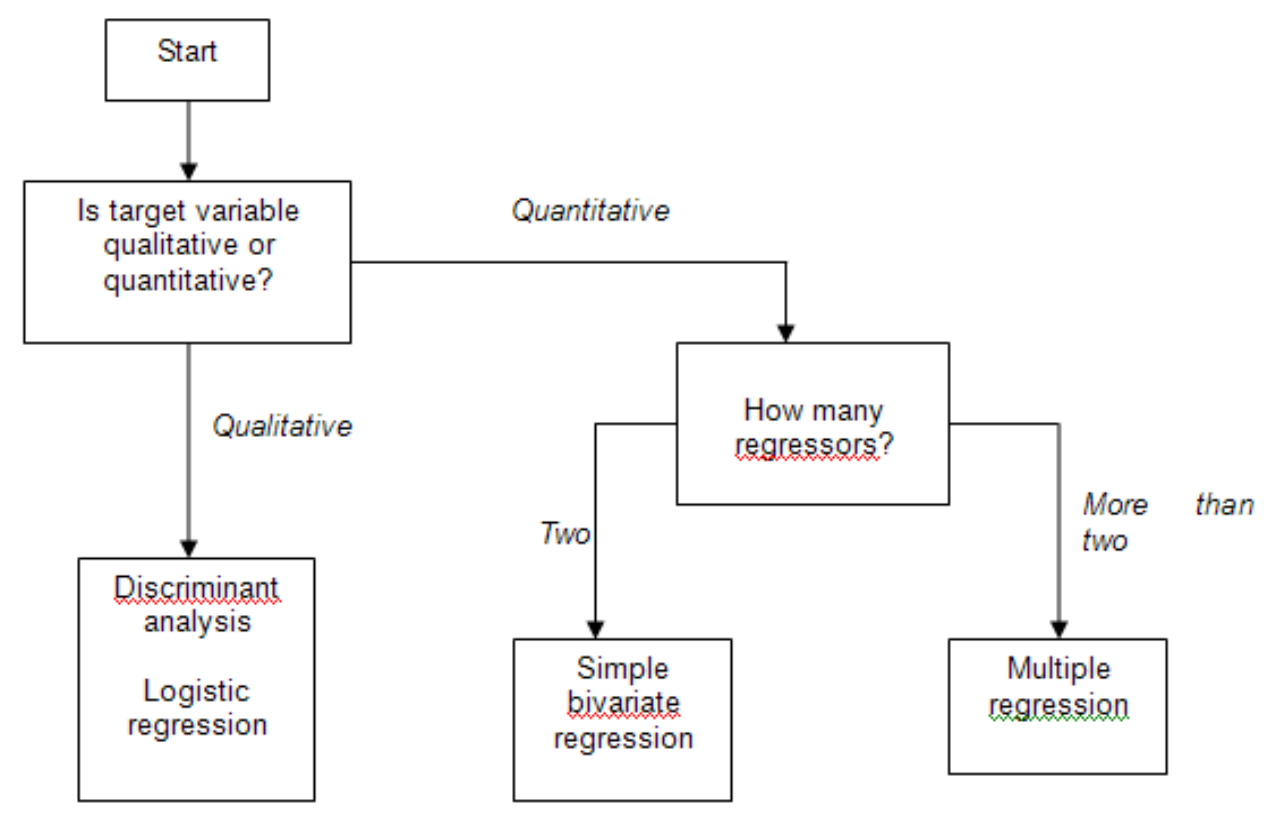

Figure 1 Statistical technique selection flow-chart (Kinnear and Gray, 2009)

Ng, A K W and Price, N D F (2010) 'Optimizing the time performance of subcontractors in the building projects', Australasian Journal of Construction Economics and Building, 10 (1/2) 90-102 
The literature review undertaken shows that multiple regression analysis is a common method for the researches involving forecasting models. Regression techniques often have been used because of their relative simplicity in both concept and application. It has the ability to develop causal models where the structural relationships of the variable can be established in a predictable and explanatory way. Walker (1995) used multiple regression analysis to build up models to forecast the time performance for projects in Australia based on four variables. Chan and Kumaraswamy (1999), and Leung and Tam (1999) applied this technique to establish models to predict the overall duration and the hoisting time for a tower crane respectively for public housing projects. Skitmore and $\mathrm{Ng}$ (2003) adopted the same statistical approach using forward cross validation procedure to forecast the construction time and cost for the projects in Australia based on six variables. For the multiple regression equations generated in this study, the time performance is the dependent variable and the six critical site coordination problems are the independent variables as per Equation 1.

Time performance $=a+b_{1}$ SCP $1+b_{2} S C P 2+b_{3}$ SCP $3+b_{4}$ SCP4 $+b_{5}$ SCP $5+b_{6}$ SCP6

Where SCPi (critical site coordination problems) are the independent variables

Time performance is the dependent variable

$a$ is a constant which is the $y$-intercept

$b_{i}$ is the partial regression coefficient for SCP

\section{Equation 1: Form of multiple regression equation}

Some of the variables of the regression equations can be eliminated without having significant impact to the accuracy of the regression equations. An analysis using six independent variables can generate sixty-three different computations. The backward elimination method was adopted to reduce the number of computations. The variable was eliminated if probability of F-to-remove was equal or greater than 0.100 . In each stage of elimination process, the most insignificant independent variable was removed. The process would be terminated when no variable satisfied the elimination condition such that the 'most critical' site coordination problems were kept in the last stage of regression equation.

\section{Validation}

The major conceptual limitation of all regression techniques is that one can only ascertain relationships, but never be sure about the underlying causal mechanism. For cross reference purposes, the neural networks technique was adopted to validate whether multiple regression is an appropriate form to represent the relationship between the site critical site coordination problems and the time performance. Neural networks analysis was commonly adopted in recent research because it is designed to capture functional forms automatically, allowing the uncovering of hidden nonlinear relationships between the modeling variables. The models formulated by Bhokha and Ogunlana (1999), based on eleven independent variables and a three-layered back-propagation network to forecast the construction duration at the predesign stage of buildings in Greater Bangkok, and the model formulated by Khosrowshahi (1999), based on eleven variables and a stochastic back-propagation paradigm with one hidden layer to predict the performance of the contractor at tender stage are typical applications of neural network analysis. This technique was also widely adopted in other studies such as: forecasting the cost index (Wang and Mei, 1998) and equipment productivity (Ok and Sinha, 2006); selection of vertical formwork systems (Tam et al, 2005); and assessing the maintainability of building façade (Chew, Silva and Tan, 2004).

NeuroShell2 software was selected for this study. A three-layer back-propagation paradigm neural network model was used to analyse the data. Ten per cent of the data were extracted as the 'test set' for the network. As the nature of the problem is not a simple problem, complex

Ng, A K W and Price, N D F (2010) 'Optimizing the time performance of subcontractors in the building projects', Australasian Journal of Construction Economics and Building, 10 (1/2) 90-102 
and noisy mode was selected. This action set the learning rate and momentum factors to 0.05 and 0.5 respectively. The number of hidden neurons was set to default number. The calibration interval was set to 50 in order to achieve maximum accuracy. The training was stopped when the new test set average errors was climbing generally or at least not close to the lowest that has been shown. This software would compile a file to compare the actual and predicted outputs, and calculate the correlation coefficient of the hidden network which could be used to measure the reliability of the network analysis.

\section{Data Analysis}

\section{Respondents}

One hundred and seventeen replies were received in this questionnaire survey. The respondents are classified into three categories and are summarized in Table 3.

\begin{tabular}{|l|c|}
\hline \multicolumn{1}{|c|}{ Type } & Number of reply \\
\hline Finishing work subcontractors & 43 \\
\hline Structural work subcontractors & 34 \\
\hline Building services work subcontractors & 40 \\
\hline Total & 117 \\
\hline
\end{tabular}

Table 3 Type of respondent

\section{Coding System}

The coding system shown in Table 2 and Table 4 is used to simplify the description of the repeated terms and enhance the understanding of the flow of the data analysis work in this paper. In this study, the multiple regression analysis covered one main model that included all replies and three sub-models for each type of subcontractors.

\begin{tabular}{|c|c|l|}
\hline Model code & Type of model & \multicolumn{1}{|c|}{ Type of subcontractor } \\
\hline Time-All & Main model & All type of subcontractors \\
\hline Time-Fin & Sub-model & Finishing work subcontractors \\
\hline Time-Str & Sub-model & Structural work subcontractors \\
\hline Time-BS & Sub-model & Building services work subcontractors \\
\hline
\end{tabular}

Table 4 Subcontractor model coding system

The regression equations of the models comprised six independent variables. For ease of reference, the regression equation containing all the variables is called standard form regression equation. The last stage regression equation containing the 'most critical' site coordination problems generated in the backward elimination process is called the simple form regression equation. Table 5 lists the regression equation codes for different models.

\begin{tabular}{|l|l|}
\hline Regression equation code & Form of regression equation \\
\hline Time-All-1 & Standard form \\
\hline Time-All-final & Simple form \\
\hline Time-Fin-1 & Standard form \\
\hline Time-Fin-final & Simple form \\
\hline Time-Str-1 & Standard form \\
\hline Time-Str-final & Simple form \\
\hline Time-BS-1 & Standard form \\
\hline Time-BS-final & Simple form \\
\hline
\end{tabular}

Table 5 Regression equation coding system

Ng, A K W and Price, N D F (2010) 'Optimizing the time performance of subcontractors in the building projects', Australasian Journal of Construction Economics and Building, 10 (1/2) 90-102 


\section{Descriptive Statistics}

Table 6 summarizes the descriptive statistics for the achievements in the time performance in the current projects of the respondents. The mean score is around 6.94. This reflects that most of the respondents were able to achieve around 70 per cent of their target standards in time performance. The standard deviation is not high. Only around 10 per cent of the respondents claimed that their projects could fully achieve the planned targets.

\begin{tabular}{|c|c|c|c|c|}
\hline Project outcome & $\begin{array}{c}\text { Mean score for } \\
\text { achievement in } \\
\text { project outcome }\end{array}$ & $\begin{array}{c}\text { Standard } \\
\text { deviation }\end{array}$ & $\begin{array}{c}\text { Maximum } \\
\text { score }\end{array}$ & $\begin{array}{c}\text { Minimum } \\
\text { score }\end{array}$ \\
\hline Time & 6.940 & 1.579 & 10.0 & 1.0 \\
\hline
\end{tabular}

Table 6 Descriptive statistics for time performance achievement

\section{Outlier}

Mahalanobis statistical method was adopted to detect extreme cases. Two outlier cases were found and deleted from the data pool in order to achieve a more accurate result. One hundred and fifteen cases were eventually included in the multiple regression analysis.

\section{Analysis for All Type of Subcontractors (Time-All) \\ Correlation coefficients of Time-All model}

Table 7 summarizes the Pearson correlation coefficient ( $r$ ), which describes how well the model fits the data, of the six site coordination problems in a descending order of priority of their absolute values. All the correlation coefficients are of negative values because the time performance achievement of the subcontractors would be deteriorated with the increase in occurrence of the site coordination problems. Four out of the six site coordination problems have good correlation with time performance as their absolute scores are above 0.5 .

\begin{tabular}{|c|c|}
\hline Variable & $\begin{array}{c}\text { Pearson correlation } \\
\text { coefficient }(\boldsymbol{r})\end{array}$ \\
\hline SCP3 & -0.666 \\
\hline SCP2 & -0.650 \\
\hline SCP1 & -0.627 \\
\hline SCP4 & -0.560 \\
\hline SCP6 & -0.411 \\
\hline SCP5 & -0.392 \\
\hline
\end{tabular}

Table 7 Correlation coefficients of Time-All model

\section{Selecting variables for Time-All model}

Four stage equations were computed in the backward elimination analysis as shown in Table 8. SCP1, SCP2 and SCP3 were kept in the Time-All-final regression equation. This shows that subcontractors' time performance mainly depends on the occurrence of short notice to commence site work (SCP1), late to provide plant support (SCP2) and interfacing work by other subcontractor not yet completed (SCP3).

\begin{tabular}{|c|c|}
\hline Model & Regression equation \\
\hline Time-All-1 & $\begin{aligned} \text { Time }= & 11.645-0.229 \times S C P 1-0.343 \times S C P 2-0.314 \times S C P 3 \\
& -0.031 \times S C P 4+0.001 \times S C P 5-0.068 \times S C P 6\end{aligned}$ \\
\hline Time-All-2 & $\begin{aligned} \text { Time }= & 11.647-0.229 \times S C P 1-0.342 \times S C P 2-0.314 \times S C P 3- \\
& 0.031 \times S C P 4-0.068 \times S C P 6\end{aligned}$ \\
\hline Time-All-3 & $\begin{aligned} \text { Time }= & 11.594-0.239 \times S C P 1-0.354 \times S C P 2-0.315 \times S C P 3- \\
& 0.071 \times S C P 6\end{aligned}$ \\
\hline Time-All-final & Time $=11.384-0.259 \times S C P 1-0.368 \times S C P 2-0.320 \times S C P 3$ \\
\hline
\end{tabular}

Table 8 Regression equations of Time-All model

Ng, A K W and Price, N D F (2010) 'Optimizing the time performance of subcontractors in the building projects', Australasian Journal of Construction Economics and Building, 10 (1/2) 90-102 


\section{Explaining the variability of Time-All model}

$\mathrm{R}$ is the absolute value of Pearson correlation coefficient $(r)$. R and $R$ Square describes what proportion of the variability of the dependent variable is explained by the regression equation. Adjusted R Square can estimate how well the equation fits another set of data from the same population. Table 9 summarizes the R, R Square and Adjusted R Square for the four stage regression equations. All the four stage regression equations are closely related to time performance as their $R$ values are over 0.7 . The $R$ values for first two stage regression equations are the same. SCP5 and SCP4 are thus not too critical to subcontractors' time performance.

\begin{tabular}{|c|c|c|c|c|}
\hline Model & $\begin{array}{c}\text { Variable } \\
\text { removed }\end{array}$ & R & R Square & $\begin{array}{c}\text { Adjusted R } \\
\text { Square }\end{array}$ \\
\hline Time-All-1 & & 0.762 & 0.581 & 0.577 \\
\hline Time-All-2 & SCP5 & 0.762 & 0.581 & 0.561 \\
\hline Time-All-3 & SCP4 & 0.762 & 0.580 & 0.565 \\
\hline Time-All-final & SCP6 & 0.760 & 0.577 & 0.566 \\
\hline
\end{tabular}

Table 9 R, R Square and Adjusted R Square values of Time-All model

\section{Analysis for Finishing Work Subcontractors (Time-Fin) \\ Correlation coefficients of Time-Fin model}

Forty-three out of the 117 respondents were finishing work subcontractors. The site problems are strongly related to time performance in the finishing work subcontracts as all their absolute $r$ coefficients are above 0.5 as shown in Table 10. SCP2, SCP4 and SCP1 are very strongly related to time performance as their absolute values are over 0.75 . Compared with the Time-All model, all the variables of Time-Fin model have higher absolute value. This indicates that the site coordination problems of the finishing work subcontractors are more correlated to time performance.

\begin{tabular}{|c|c|c|c|}
\hline Variable & A & B & C \\
\hline SCP2 & -0.823 & -0.650 & 0.173 \\
\hline SCP4 & -0.781 & -0.560 & 0.221 \\
\hline SCP1 & -0.763 & -0.627 & 0.136 \\
\hline SCP3 & -0.683 & -0.666 & 0.017 \\
\hline SCP6 & -0.648 & -0.411 & 0.237 \\
\hline SCP5 & -0.529 & -0.392 & 0.137 \\
\hline
\end{tabular}

Table 10 Correlation coefficients of Time-Fin model

\footnotetext{
A: $\quad$ Pearson correlation coefficient $(r)$ of Time-Fin model

B: $\quad$ Pearson correlation coefficient $(r)$ of Time-All model

C: Absolute value of the difference between $A$ and $B$
}

\section{Selecting variables for Time-Fin model}

The Time-Fin-final regression equation listed in Table 11 shows that time performance of finishing work subcontractors depends mainly on three site coordination problems: late to provide plant support (SCP2), interfacing work not accurately completed (SCP4) and construction information unclear or contradictory (SCP6). The Time-All-final equation also consists of three independent variables. However, only SCP2 is common in both of the Time-All-final equation and SP-Time-Fin-final equation. 


\begin{tabular}{|c|c|}
\hline Model & Regression equation \\
\hline Time-Fin-1 & $\begin{aligned} \text { Time }= & 13.896-0.265 \times \text { SCP1 }-0.429 \times \text { SCP2 }-0.094 \times S C P 3- \\
& 0.300 \times S C P 4-0.158 \times S C P 5-0.194 \times S C P 6\end{aligned}$ \\
\hline Time-Fin-2 & $\begin{aligned} \text { Time }= & 13.794-0.293 \times S C P 1-0.466 \times S C P 2-0.280 \times S C P 4- \\
& 0.166 \times S C P 5-0.223 \times S C P 6\end{aligned}$ \\
\hline Time-Fin-3 & $\begin{aligned} \text { Time }= & 13.456-0.256 \times S C P 1-0.530 \times S C P 2-0.290 \times S C P 4- \\
& 0.282 \times S C P 6\end{aligned}$ \\
\hline Time-Fin-final & Time $=13.375-0.607 \times S C P 2-0.384 \times S C P 4-0.333 \times S C P 6$ \\
\hline
\end{tabular}

Table 11 Regression equations of Time-Fin model

\section{Explaining the variability of Time-Fin model}

Table 12 shows that the four stage equations are very strongly related to time performance as their $\mathrm{R}$ values are around 0.9. Time-Fin-final equation is more strongly related to time performance than Time-All-final equation as its $R$ value is 0.130 higher.

\begin{tabular}{|c|c|c|c|c|}
\hline Model & $\begin{array}{c}\text { Variable } \\
\text { removed }\end{array}$ & $\mathbf{R}$ & R Square & $\begin{array}{c}\text { Adjusted R } \\
\text { Square }\end{array}$ \\
\hline Time-Fin-1 & & 0.906 & 0.821 & 0.791 \\
\hline Time-Fin-2 & SCP3 & 0.905 & 0.818 & 0.794 \\
\hline Time-Fin-3 & SCP5 & 0.898 & 0.806 & 0.786 \\
\hline Time-Fin-final & SCP1 & 0.890 & 0.792 & 0.776 \\
\hline
\end{tabular}

Table 12 R, R Square and Adjusted R Square values of Time-Fin model

\section{Analysis for Structural Work Subcontractors (Time-Str)}

\section{Correlation coefficients of Time-Str model}

Thirty-four out of the 117 replies were from the structural work subcontractors. Table 13 shows that there are only slight differences in the $r$ values of the variables between Time-Str model and Time-All model. Four variables have absolute $r$ coefficients above 0.5.

\begin{tabular}{|c|c|c|c|}
\hline Variables & A & B & C \\
\hline SCP3 & -0.742 & -0.666 & 0.076 \\
\hline SCP2 & -0.724 & -0.650 & 0.074 \\
\hline SCP1 & -0.692 & -0.627 & 0.065 \\
\hline SCP4 & -0.532 & -0.560 & -0.028 \\
\hline SCP5 & -0.409 & -0.392 & 0.017 \\
\hline SCP6 & -0.346 & -0.411 & -0.065 \\
\hline
\end{tabular}

Table 13 Correlation coefficients of Time-Str model

\footnotetext{
A: Pearson correlation coefficient $(r)$ of SP-Time-Str model

B: Pearson correlation coefficient ( $r$ ) of SP-Time-All model

C: Absolute value of the difference between $A$ and $B$.
}

\section{Selecting variables for Time-Str model}

The Time-Str-final equation shown in Table 14 consists of SCP1, SCP2 and SCP3 which are the same of Time-All-final equation. This indicates that time performance of the structural 
subcontractors depends mainly on three site coordination problem: short notice to commence site work (SCP1), late to provide plant support (SCP2) and interfacing work by other subcontractor not yet completed (SCP3).

\begin{tabular}{|c|c|}
\hline Model & Regression equation \\
\hline Time-Str-1 & $\begin{aligned} \text { Time }= & 12.299-0.350 \times S C P 1-0.421 \times S C P 2-0.420 \times S C P 3+ \\
& 0.117 \times S C P 4+0.119 \times S C P 5-0.155 \times S C P 6\end{aligned}$ \\
\hline Time-Str-2 & $\begin{aligned} \text { Time }= & 12.542-0.314 \times S C P 1-0.403 \times S C P 2-0.422 \times S C P 3+ \\
& 0.127 \times S C P 4-0.137 \times S C P 6\end{aligned}$ \\
\hline Time-Str-3 & $\begin{aligned} \text { Time }= & 12.658-0.285 x \text { SCP1 }-0.352 x \text { SCP2 }-0.393 x \text { SCP3 }- \\
& 0.114 x \text { SCP } 6\end{aligned}$ \\
\hline Time-Str-final & Time $=12.227-0.271 \times$ SCP1- $0.407 \times S C P 2-0.394 \times S C P 3$ \\
\hline
\end{tabular}

Table 14 Regression equations of Time-Str model

\section{Explaining the variability for Time-Str model}

Table 15 shows that the four stage equations of Time-Str model are very strongly related to time performance as their $\mathrm{R}$ values are above 0.8 . The change in $\mathrm{R}$ values is consistent in each stage of elimination process. SCP4, SCP5 and SCP6 have similar amount of influence on the time performance of the structural work subcontractors. Time-Str-final equation is slightly stronger related to time performance than that of Time-All-final equation as its $R$ value is just 0.071 higher.

\begin{tabular}{|c|c|c|c|c|}
\hline Model & $\begin{array}{c}\text { Variable } \\
\text { removed }\end{array}$ & R & R Square & $\begin{array}{c}\text { Adjusted R } \\
\text { Square }\end{array}$ \\
\hline Time-Str-1 & & 0.844 & 0.712 & 0.648 \\
\hline Time-Str-2 & SCP 5 & 0.840 & 0.706 & 0.654 \\
\hline Time-Str-3 & SCP 4 & 0.836 & 0.698 & 0.657 \\
\hline Time-Str-Final & SCP 6 & 0.831 & 0.697 & 0.660 \\
\hline
\end{tabular}

Table 15 R, R Square and Adjusted R Square values of Time-Str model

\section{Analysis for Building Services Work Subcontractors (Time-BS)}

\section{Correlation coefficients of Time-BS model}

Forty out of the 117 replies were from the building services work subcontractors. In the building services work, only SCP3 is strongly related to time performance as its absolute $r$ coefficient is above 0.7 as shown in Table 16. Four out of six variables have the absolute $r$ coefficients lower than 0.5. Compared with the Time-All model, four variables have lower absolute $r$ coefficients.

\begin{tabular}{|c|c|c|c|}
\hline Variables & A & B & C \\
\hline SCP3 & -0.711 & -0.666 & 0.045 \\
\hline SCP1 & -0.513 & -0.627 & -0.114 \\
\hline SCP2 & -0.418 & -0.650 & -0.232 \\
\hline SCP5 & -0.394 & -0.392 & 0.002 \\
\hline SCP4 & -0.371 & -0.560 & -0.189 \\
\hline SCP6 & -0.258 & -0.411 & -0.153 \\
\hline
\end{tabular}

Table 16 Correlation coefficients of Time-BS model

\footnotetext{
A: $\quad$ Pearson correlation coefficient $(r)$ of Time-BS model

$\mathrm{B}$ : Pearson correlation coefficient ( $r$ ) of Time-All model

C: Absolute value of the difference between $A$ and $B$
}

Ng, A K W and Price, N D F (2010) 'Optimizing the time performance of subcontractors in the building projects', Australasian Journal of Construction Economics and Building, 10 (1/2) 90-102 


\section{Selecting variables for Time-BS model}

Six stage equations summarized in Table 17 were established in the backward elimination analysis. The Time-BS-final equation only has one independent variable, SCP3. This indicates that the time performance of the building services work subcontractors depends heavily the occurrence of incomplete interfacing work (SCP3). This result matches the high absolute $r$ coefficient of SCP3.

\begin{tabular}{|c|c|}
\hline Model & Regression equations \\
\hline Time-BS & $\begin{aligned} \text { Time }= & 8.906-0.075 \times S C P 1-0.120 \times S C P 2-0.498 \times S C P 3+ \\
& 0.191 \times S C P 4-0.047 \times S C P 5+0.062 \times S C P 6\end{aligned}$ \\
\hline Time-BS-1 & $\begin{aligned} \text { Time }= & 8.907-0.057 \times S C P 1-0.108 \times S C P 2-0.514 \times S C P 3+ \\
& 0.160 \times S C P 4+0.046 \times S C P 6\end{aligned}$ \\
\hline Time-BS-3 & $\begin{aligned} \text { Time }= & 8.922-0.098 \times S C P 2-0.540 \times S C P 3+0.137 \times S C P 4+ \\
& 0.029 \times S C P 6\end{aligned}$ \\
\hline Time-BS-4 & Time $=9.018-0.090 \times S C P 2-0.536 \times S C P 3+0.141 \times S C P 4$ \\
\hline Time-BS-5 & Time $=8.996-0.554 \times S C P 3+0.097 \times$ SCP 4 \\
\hline Time-BS-final & Time $=9.361-0.506 \times \mathrm{SCP} 3$ \\
\hline
\end{tabular}

Table 17 Regression equations of Time-BS model

\section{Explaining the variability of Time-BS model}

The $\mathrm{R}$ values for the six stage regression equations of SP-Time-BS model shown in Table 18 are all above 7, which show that they are all strongly related to the time performance. The Time-BS-1 equation and Time-BS-2 equation have the same R values. SCP5 thus has no significant impact to the time performance of the structural subcontractors. The different between the Time-BS-1 and Time-BS-final is just 0.011, which reflects that SCP3 is dominant in the time performance analysis. Time-BS-final equation is not as accurate as Time-All-final equation in explain the time performance for subcontractors as its $R$ value is 0.049 lower.

\begin{tabular}{|c|c|c|c|c|}
\hline Model & $\begin{array}{c}\text { Variable } \\
\text { removed }\end{array}$ & R & R Square & $\begin{array}{c}\text { Adjusted R } \\
\text { Square }\end{array}$ \\
\hline Time-BS-1 & & 0.722 & 0.522 & 0.435 \\
\hline Time-BS-2 & SCP5 & 0.722 & 0.521 & 0.450 \\
\hline Time-BS-3 & SCP1 & 0.721 & 0.519 & 0.464 \\
\hline Time-BS-4 & SCP6 & 0.720 & 0.518 & 0.478 \\
\hline Time-BS-5 & SCP2 & 0.716 & 0.513 & 0.487 \\
\hline Time-BS-final & SCP4 & 0.711 & 0.506 & 0.493 \\
\hline
\end{tabular}

Table 18 R, R Square and Adjusted R Square values of Time-BS model

\section{Neural network analysis}

The neural network analysis results for different models are summarised in the descending order of priority of their correlation coefficients in Table 19. All the models computed by NeuroShell2 software fit the data very well as their correlation coefficients are over 0.7. The outputs of Time-Fin models have the highest $r$ coefficients. 


\begin{tabular}{|l|c|c|c|c|}
\hline Neural network output & A & B & C & D \\
\hline Time-Fin-1 & 0.905 & 10 & 43 & 0.0035768 \\
\hline Time-Fin-final & 0.900 & 8 & 43 & 0.0067964 \\
\hline Time-Str-1 & 0.832 & 9 & 34 & 0.0007867 \\
\hline Time-Str-final & 0.873 & 8 & 34 & 0.0008179 \\
\hline Time-All-1 & 0.763 & 14 & 117 & 0.0006010 \\
\hline Time-All-final & 0.763 & 12 & 117 & 0.0006462 \\
\hline Time-BS-1 & 0.706 & 10 & 40 & 0.0000577 \\
\hline Time-BS-final & 0.772 & 7 & 40 & 0.0000046 \\
\hline
\end{tabular}

Table 19 Neural network analysis

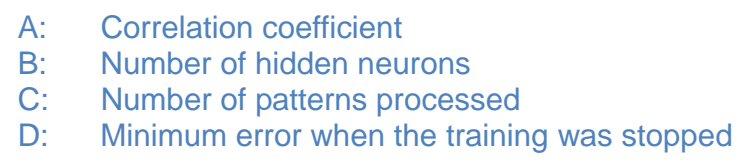

Table 20 compares the correlation coefficients of the regression equations with the neural network analysis outputs. The correlation coefficients computed by these two methods are quite consistent and the maximum difference is only 0.061 . As all the correlation coefficients are high, it is reliable to conclude that multiple regression equation is an appropriate form to explain the relationship between the time performance of subcontractors and the occurrence of the site coordination problems.

\begin{tabular}{|l|c|c|c|c|}
\hline \multicolumn{1}{|c|}{ Model } & A & B & C & D \\
\hline Time-Fin-1 & All & 0.906 & 0.905 & 0.001 \\
\hline Time-Fin-final & SCP2, SCP4, SCP6 & 0.890 & 0.900 & -0.010 \\
\hline Time-Str-1 & All & 0.844 & 0.832 & 0.012 \\
\hline Time-Str-final & SCP1, SCP2, SCP3 & 0.831 & 0.874 & -0.043 \\
\hline Time-All-1 & All & 0.762 & 0.763 & -0.001 \\
\hline Time-All-final & SCP1, SCP2, SCP3 & 0.760 & 0.763 & -0.003 \\
\hline Time-BS-1 & All & 0.722 & 0.706 & 0.016 \\
\hline Time-BS-Final & SCP3 & 0.711 & 0.772 & -0.061 \\
\hline
\end{tabular}

Table 20 Comparison of multiple regression analysis and neural network analysis

\footnotetext{
A: Independent variables included in the model

B: $\quad$ Correlation coefficient computed by multiple regression method

C: Correlation coefficient computed by neural network method

D: $\quad$ Difference of B and C
}

\section{Conclusion}

There are increasing complaints from subcontractors that they could not perform effectively and efficiently due to poor site coordination by main contractors in the Hong Kong building projects. A questionnaire survey was conducted to investigate how the site coordination problems affect the time performance of subcontractors.

The survey findings show that subcontractors in the Hong Kong building projects were only able to achieve on average 70 per cent of their planned time performance targets. Only about 10 per cent of them could complete their work according to project programs. 


\section{Relationships}

Multiple regression was used to generate equations to explain the time performance of the subcontractors based on the occurrence of critical site coordination problems. The data were also processed by neural network software as a cross check on the accuracy of the regression equations. The analysis covered one main model and three sub-models for the overall data and different types of subcontractors respectively. Table 21 summarizes the standard form regression equations for different models in descending order of their $\mathrm{R}$ values. The equations may be used to explain the relationships between time performance and site coordination problems as their $\mathrm{R}$ values are all above 0.7 .

\begin{tabular}{|c|c|c|}
\hline Model & Regression equation & $R$ value \\
\hline Time-Fin-1 & $\begin{aligned} \text { Time }= & 13.896-0.265 \times S C P 1-0.429 \times S C P 2-0.094 \times S C P 3 \\
& -0.300 \times S C P 4-0.158 \times S C P 5-0.194 \times S C P 6\end{aligned}$ & 0.906 \\
\hline Time-Str-1 & $\begin{aligned} \text { Time }= & 12.299-0.350 \times S C P 1-0.421 \times S C P 2-0.420 \times S C P 3 \\
& +0.117 \times S C P 4+0.119 \times S C P 5-0.155 \times S C P 6\end{aligned}$ & 0.844 \\
\hline Time-All-1 & $\begin{aligned} \text { Time }= & 11.645-0.229 \times S C P 1-0.343 \times S C P 2-0.314 \times S C P 3 \\
& -0.031 \times S C P 4+0.001 \times S C P 5-0.068 \times S C P 6\end{aligned}$ & 0.762 \\
\hline Time-BS-1 & $\begin{aligned} \text { Time }= & 8.906-0.075 \times \text { SCP } 1-0.120 \times S C P 2-0.498 \times S C P 3 \\
& +0.191 \times S C P 4-0.047 \times S C P 5+0.062 \times S C P 6\end{aligned}$ & 0.722 \\
\hline
\end{tabular}

Table $21 \mathrm{R}$ values for the standard form regression equation

\section{'Most critical' site coordination problems}

Some of the independent variables (critical site coordination problems) of the regression equations can be eliminated without imposing any significant influence to the dependent variable (time performance). The analysis was conducted by means of backward elimination method. The results of the analysis can enable the local main contractors to focus their efforts in handling the 'most critical' site coordination problems which are the independent variables remained in the last regression equations generated in the elimination process.

Table 22 analyses the importance of the critical site coordination problems. Late to provide plant support (SCP2) and Interfacing work not yet completed (SCP3) are the 'most critical' site coordination problems to subcontractors' time performance as they are the independent variables of three out of the four simple form regression equations in this study. Main contractor can pay less attention to insufficient construction information problem (SCP5) and contradictory construction information (SCP6) as none of the simple form regression equation has these independent variables.

\begin{tabular}{|c|c|l|}
\hline Site coordination problem & No. & \multicolumn{1}{|c|}{ Type of subcontractor } \\
\hline SCP2 & 3 & All type; Finishing work; Structural work \\
\hline SCP3 & 3 & All type; Structural work; Building services work \\
\hline SCP1 & 2 & All type; Structural work \\
\hline SCP4 & 1 & Finishing work \\
\hline SCP5 & 0 & \\
\hline SCP6 & 0 & \\
\hline
\end{tabular}

Table 22 Importance of the site coordination problem

No.: Total number of simple form regression equations consists of that site coordination problem.

Ng, A K W and Price, N D F (2010) 'Optimizing the time performance of subcontractors in the building projects', Australasian Journal of Construction Economics and Building, 10 (1/2) 90-102 


\section{References}

Bhokha S. and Ogunlana SO. (1999) 'Application of artificial neural network to forecast construction duration of buildings at the predesign stage', Engineering, Construction and Architectural Management, 1996 6/2, 133-144

Census and Statistics Department (2009) Census and Statistics, Hong Kong SAR Government

Chan, DWM. and Kumaraswamy, MM. (1999) 'Modelling and predicting construction durations in Hong Kong public housing', Construction Management and Economics, 17, 351-362

Chew M. Y. L., Silva N D. and Tan S. S. (2004) 'A neural network approach to assessing building façade maintainability in the tropics', Construction Management and Economics, 22, 581-594

Frisby, T. N. (1990) Survival in the Construction Business: Checklists for Success, R.S. Means, Kingston, Mass

Kadir, MR, Abdul, Lee, WP, Jaafar, MS, Sapuan, SM, and Ali, AAA, (2005), 'Factors affecting construction labour productivity for Malaysian residential projects', Structural Survey, 23 (1), 2005, 42-54

Khosrowshahi F. (1999) 'Neural network model for contractors' prequalification for local authority projects, Engineering, Construction and Architectural Management, 6 (3), 315-328

Kinnear, PR. and Gray, DC, (2008) SPSS15 Made Simple, Taylor \& Francis, London

Leung AWT. and Tam CM. (1999) 'Prediction of hoisting time for tower cranes for public housing construction in Hong Kong', Construction Management and Economics 17, 305-314

Ng, K. W. A. and Price, A. D. F. (2005) 'Assessing the impact of main contractor's site co-ordination on sub-contractors' performance in Hong Kong' Proceedings of the Annual Conference 2005, Association of Researchers in Construction Management, U.K

Skitmore, RM and $\mathrm{Ng}, \mathrm{ST}$, (2003) 'Forecast models for actual construction time and cost', Building and Environment, 38 (8) 1075-83

Ok, SC and Sinha, SK, (2006) 'Construction equipment productivity estimation using artificial neural network model', Construction Management and Economics, 24, 1029-1044

Sozen, Z. and Kucuk, MA, (1999) 'Secondary subcontracting in the Turkish construction industry, Construction Management and Economics, 17, 215-220

Tam, CM, Tong, TKL, Lau TCT and Chan KK, (2005) 'Selection of vertical formwork system by probabilistic neural networks models', Construction Management Economics, 23, 245-254

Walker, D. (1995) 'An investigation into construction time performance, Construction Management and Economics, 13, 263-274

Wang $\mathrm{CH}$. and Mei, $\mathrm{YH}$, (1998) 'Model for forecasting construction cost indices in Taiwan', Construction Management and Economics, 16, 147-157 